Acta Cryst. (1954). 7, 487

\title{
The Crystal Structure of $\mathrm{Cs}_{2} \mathrm{I}_{8}\left(\mathrm{CsI}_{4}\right)$
}

\author{
By E. E. Havinga, K. H. BoswiJk and E. H. Wiebenga \\ Laboratorium voor Anorganische en Physische Chemie der Rijks-Universiteit, Groningen, The Netherlands
}

(Received 15 February 1954)

\begin{abstract}
The crystal structure of $\mathrm{CsI}_{4}$ has been determined by X-ray analysis. Space group: $P 2_{1} / a ; 4 \mathrm{CsI}_{4}$ per unit cell. The signs of 60 out of the 71 observed $h 0 l$ structure factors could be calculated directly from inequalities. Inequalities were not useful in the [001] projection, but a first approximation could be obtained from Buerger's minimum function. The coordinates were refined by Fourier syntheses of the three projections and corrected for the termination of the series. The final value of the disagreement factor $R$ is 0.085 , and the standard deviation in the atomic distances is $0.02-$ $0.03 \AA$.
\end{abstract}

The structure consists of $\mathrm{Cs}^{+}$ions and flat $\left[\mathrm{I}_{3}^{-} \cdot \mathrm{I}_{2}, \mathrm{I}_{3}^{-}\right]$ions, the latter showing a weak interaction between their constituents.

\section{Introduction}

From the observed diamagnetism of $\mathrm{CsI}_{4}$ (Hubard, 1942) it is likely that the empirical formula of this compound must be doubled since $\mathrm{I}_{4}^{-}$ions should be paramagnetic, because of their odd number of electrons. Formulas as $\mathrm{Cs}_{2} \mathrm{I}_{8}$ and $2 \mathrm{CsI}_{3} \cdot \mathrm{I}_{2}$ have been suggested. It was the purpose of the present investigation to obtain detailed information on the structure of this polyiodide.

\section{Experimental}

\section{Materials}

A mixture of $5.00 \mathrm{~g}$. CsI, $2 \cdot 015 \mathrm{~g}$. $\mathrm{I}_{2}$ and $73.69 \mathrm{~g}$. $\mathrm{H}_{2} \mathrm{O}$ was heated in a closed vessel at $90^{\circ} \mathrm{C}$. until it became homogeneous, and was then cooled slowly to $25^{\circ}$ C. After 1-2 days $\mathrm{CsI}_{4}$ crystallized from this solution in violet monoclinic plates $\{100\}$, showing also the forms $\{001\}$ and $\{201\}$. The crystals were dried in a desiccator over sulphuric acid. The composition was checked by chemical analysis. The m.p. was 139$140^{\circ}$ C. (cf. Briggs, Greenawald \& Leonard, 1930).

\section{Unit cell and space group}

The cell dimensions were obtained from rotationand Weissenberg photographs about the $a, b$ and $c$ axes, using Ni-filtered $\mathrm{Cu}$ radiation and $\mathrm{Zr}$-filtered Mo radiation. With $\lambda(\mathrm{Cu} K \alpha)=1.5418 \AA$ and $\lambda($ Mo $K \alpha)=0.7107 \AA$ the following values were observed:

$$
\begin{gathered}
a=11 \cdot 19_{ \pm 0} \cdot 05, \quad b=9 \cdot 00_{ \pm} 0 \cdot 04, \quad c=10 \cdot 23 \pm 0 \cdot 05 \AA, \\
\beta=114^{\circ} 20^{\prime} \pm 10^{\prime} .
\end{gathered}
$$

These cell dimensions agree with old optical goniometric measurements by Penfield (Wells, Wheeler \& Penfield, 1893) on a polyiodide, which was thought to be $\mathrm{CsI}_{5}$ and which was described as triclinic with

$$
\begin{gathered}
a^{\prime}: b^{\prime}: c^{\prime}=0.9890: 1: 0.42765, \\
\alpha^{\prime}=96^{\circ} 56^{\prime}, \beta^{\prime}=89^{\circ} 55 \frac{1^{\prime}}{2}, \gamma^{\prime}=90^{\circ} 21 \frac{1}{2}^{\prime} .
\end{gathered}
$$

Transforming the axes of $\mathrm{CsI}_{4}$ by the matrix

$$
\begin{gathered}
\left\|\begin{array}{lll}
0 & 3 & 0 \\
1 & 0 & 2 \\
1 & 0 & 1
\end{array}\right\|, \quad \text { we obtain } \\
a^{\prime}: b^{\prime}: c^{\prime}=0.998: 1: 0.430, \\
\alpha^{\prime}=96^{\circ} 44^{\prime} \beta^{\prime}=90^{\circ}, \gamma^{\prime}=90^{\circ},
\end{gathered}
$$

in close agreement with Penfield's data. This makes it very probable that Penfield's measurements refer to $\mathrm{CsI}_{4}$ (see also Briggs \& Hubard, 1941).

With $4 \mathrm{CsI}_{4}$ per unit cell the calculated density is 4.53 g.cm..$^{-3}$, which is in satisfactory agreement with the measured density, 4.62 g.cm. ${ }^{-3}$.

Since it was not possible to find a liquid by which $\mathrm{CsI}_{4}$ was not decomposed, the density was measured in air using a volumetric method (Henglein \& Roth, 1923). These measurements were made by $\mathrm{Mr} \mathrm{H}$. A. Tasman, whose assistance is gratefully acknowledged.

The following systematic extinctions were observed: $h 0 l$ for $h$ odd and $0 k 0$ for $k$ odd. The space group $P 2_{1} / a$, which accounts for these extinctions, was accepted.

\section{Structure factors}

The intensities of the $h 0 l, h k 0$ and $0 k l$ reflexions were measured on integrated Weissenberg photographs (Wiebenga \& Smits, 1950). The very weak reflexions were estimated visually on ordinary Weissenberg photographs of long exposure time. The exposures were taken with Zr-filtered Mo radiation.

Small needles along the $b$ or $c$ axis, having crosssections of approximately $0.03 \times 0.04 \mathrm{~mm}$., could be obtained by cleavage from larger crystals. This permitted the absorption correction to be neglected for the $h 0 l$ and $h k 0$ reflexions. The $0 k l$ reflexions had to be obtained from a crystal of very irregular shape with dimensions varying from 0.02 to $0.1 \mathrm{~mm}$. The influence of absorption was minimized for this specimen by taking an anti-equi-inclination Weissenberg photo- 
graph (Kartha, 1952) and applying a graphical absorption correction.

After taking into account the Lorentz and polarization factors the mutually independent structure factors of $71 h 0 l$ reflexions, $64 h k 0$ reflexions and $490 k l$ reflexions were at our disposal.

\section{Determination of the structure}

\section{The [010] projection}

By applying Wilson's method (Wilson, 1942) the unitary structure factors were obtained. Several high values of $U_{h 0 l}$, up to $0 \cdot 70$, were observed, so that an application of inequality relationships between these structure factors looked promising. Making use of the inequalities of Harker \& Kasper (1948) in the form given by Gillis $(1948 a, b)$, the signs of $60 h 0 l$ structure factors could be obtained.

In the Fourier synthesis based on these 60 terms all atoms were resolved. After calculating the structure factors it appeared that the signs of only 5 of the 60 structure factors had to be changed. The [010] projection was refined by the Fourier method, correcting the coordinates for finite-series errors by the 'backshift' method (Booth, 1946).

\section{The [001] projection}

For this projection the values of the unitary structure factors were too low to make a fruitful application of inequalities possible. Making use, however, of the known $x$ coordinates and the expected minimum distance between the atoms, it proved to be possible to locate a single peak in the [001] Patterson projection (Fig. 1). Starting from this single peak, Buerger's minimum function $M_{4}$ (Buerger, 1951) was obtained (Fig. 2). Guided by the minimum function it was possible, after some trial, to get a satisfactory agreement between calculated and observed structure factors, from which the signs of $45 h k 0$ structure factors

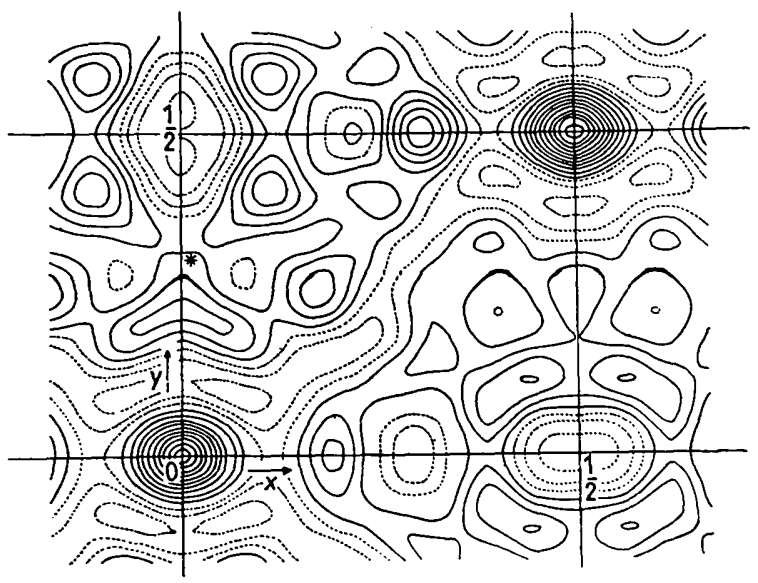

Fig. 1. The [001] Patterson projection. The single peak is indicated by an asterisk. Contours are at equal intervals on an arbitrary scale.

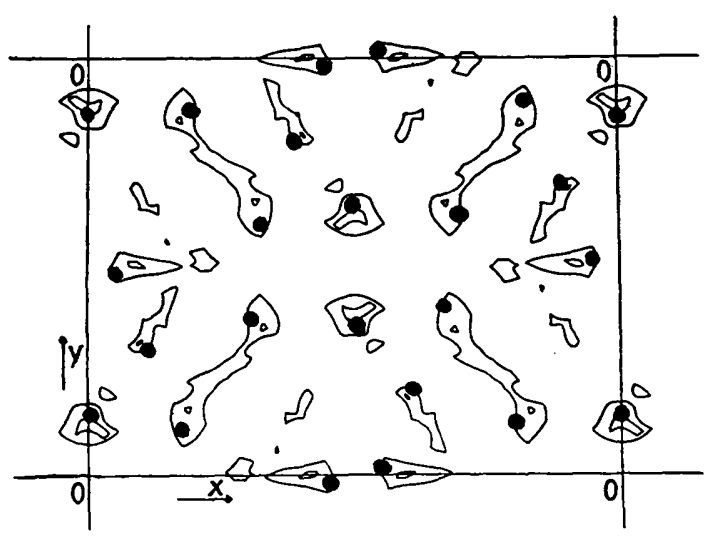

Fig. 2. Buerger's minimum function, $M_{4}$, constructed from the [001] Patterson projection. The final atomic positions are indicated by heavy dots.

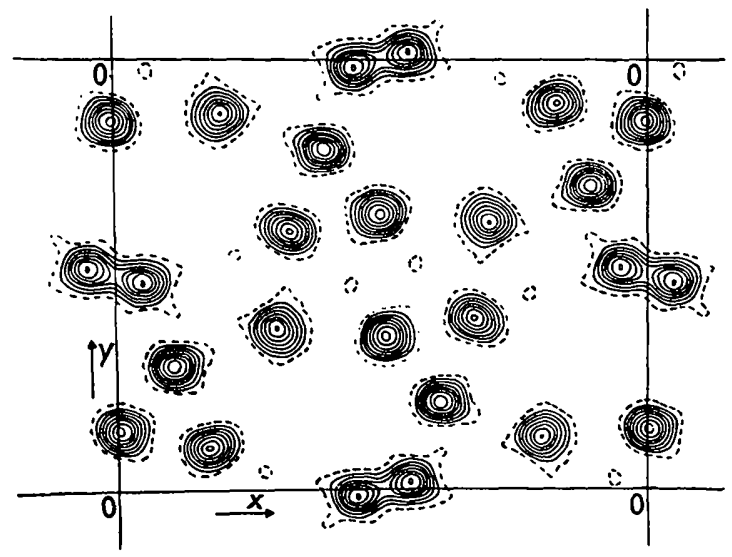

Fig. 3. The final [001] Fourier synthesis of $\mathrm{Cs}_{2} \mathrm{I}_{8}$. Contours are drawn at intervals of $10 \mathrm{e} . \AA^{-2}$, the $10 \mathrm{e} . \AA^{-2}$ line being broken.

could be determined. The coordinates were refined by Fourier syntheses and were corrected for the influence of termination of the series. The final contour map is shown in Fig. 3.

\section{The [100] projection}

Using the coordinates deduced from the other two projections, the final Fourier synthesis for this projection could be computed. The coordinates from this synthesis were also corrected for the finite-series effect.

As final coordinates (Table 1) the average values

\section{Table 1. Final coordinates}

$\begin{array}{lccc} & x & y & z \\ \text { Cs } & 0 \cdot 200 & 0 \cdot 876 & 0 \cdot 277 \\ \mathrm{I}_{1} & 0 \cdot 006 & 0 \cdot 143 & 0 \cdot 446 \\ \mathrm{I}_{2} & 0 \cdot 050 & 0 \cdot 485 & 0 \cdot 328 \\ \mathrm{I}_{3} & 0 \cdot 107 & 0 \cdot 292 & 0 \cdot 121 \\ \mathrm{I}_{4} & 0 \cdot 174 & 0 \cdot 100 & 0 \cdot 941\end{array}$

of each coordinate deduced from two projections were taken. 
With these coordinates the value of $R=$ $\Sigma\left\{\left|F_{o}\right|-\left|F_{c}\right|\right\} \div \Sigma\left|F_{o}\right|$ was $0 \cdot 085$, the summations being taken over all observed reflexions. In the calculated structure factors an isotropic temperature factor $\exp \left[-3 \cdot 5(\sin \theta / \lambda)^{2}\right]$ was introduced.*

\section{Discussion}

\section{Accuracy}

The accuracy of the final coordinates was estimated by comparing the two independent values obtained for 14 coordinates from the three projections. The r.m.s. error of the average value was $0.015 \AA$ for each coordinate direction. The resulting standard error in the atomic distances is $0.02 \AA$ for two symmetrically independent atoms and $0.03 \AA$ for symmetrically related atoms. In addition to these standard deviations the atomic distances are subject to a maximum error of approximately $0.6 \%$ due to inaccuracy of the cell dimensions. The standard deviation in the bond angles is approximately $1^{\circ}$.

It was noticed that the standard deviations calculated by the formula of Cruickshank (1949) are approximately three times as small as those calculated in the way mentioned above. It is suspected that the discrepancy is due to an imperfect correction for the termination of the series. The back shifts, which had to be taken into account in subsequent stages of refinement, appeared to be not entirely consistent.

\section{Description and discussion of the structure}

From the interatomic distances it may concluded that the structure (Fig. 4) consists of $\mathrm{Cs}^{+}$ions, $\mathrm{I}_{3}^{-}$ions and $I_{2}$ molecules. Pairs of $I_{3}^{-}$ions form with one $I_{2}$

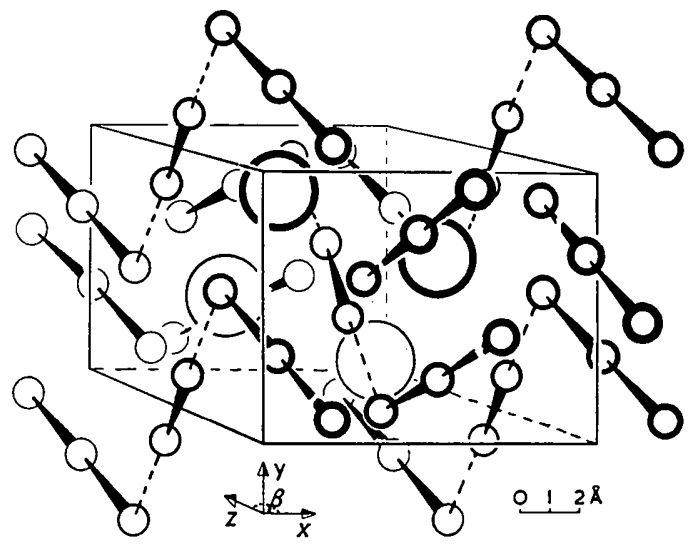

Fig. 4. The crystal structure of $\mathrm{Cs}_{2} \mathrm{I}_{8}$.

* A table of observed and calculated structure factors for some 227 reflexions has been deposited as Document No.4214 with the ADI Auxiliary, Publications Project, Photoduplication Service, Library of Congress, Washington 25, D.C., U.S.A. A copy may be secured by citing the Document number and by remitting $\$ 1.25$ for photoprints, or $\$ 1.25$ for $35 \mathrm{~mm}$. microfilm. Advance payment is required. Make cheques or money orders payable to: Chief, Photoduplication Service, Library of Congress. molecule a larger very nearly flat unit $\mathrm{I}_{8}^{--}$(Fig. 5) which is located approximately in the plane

$$
6 \cdot 45 x+0 \cdot 11 y+2 z=1
$$

or the plane related to it by symmetry.

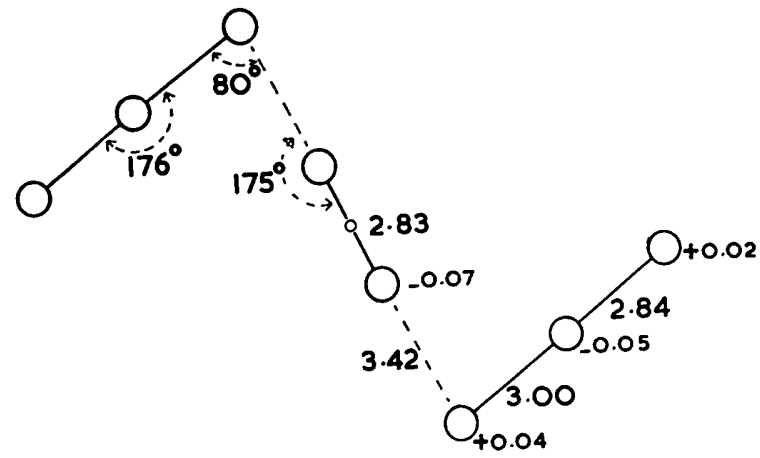

Fig. 5. Bond lengths $(\AA)$ and valence angles in the $I_{8}^{--}$ion. The smaller figures represent the deviations from an exactly planar configuration.

The minimum distance between iodine atoms belonging to different $\mathrm{I}_{8}^{--}$units is $3.9 \AA$. Distances between a $\mathrm{Cs}^{+}$ion and eight iodine atoms vary from 3.85 to $4.07 \AA$, those between the $\mathrm{Cs}^{+}$ion and two other iodine atoms are 4.33 and $4.38 \AA$, all other Cs- $\mathrm{I}$ distances are larger than $5 \cdot 3 \AA$. The minimum distance $(3.85 \AA)$ between $\mathrm{Cs}$ and I equals the sum of the ionic radii of $\mathrm{Cs}^{+}$and $\mathrm{I}^{-}$.

A discussion of the structure of the $I_{8}^{--}$ion may be given by comparing the atomic distances in this ion with those observed in $I_{2}$ (Harris, Mack \& Blake, 1928; Hassel \& Viervoll, 1947), $\mathrm{NH}_{4} \mathrm{I}_{3}$ (Mooney, 1935) and $\mathrm{N}\left(\mathrm{CH}_{3}\right)_{4} \mathrm{I}_{5}$ (Hach \& Rundle, 1951). The distance $(2.83 \AA)$ between the two central iodine atoms in $\mathrm{I}_{8}^{--}$ is significantly larger than that observed between two bonded atoms in solid iodine $(2 \cdot 70 \AA)$, whereas the distance $\left(3.42 \AA\right.$ between $\mathrm{I}_{3}^{-}$and $\mathrm{I}_{2}$ in the $\mathrm{I}_{8}^{--}$ion is shorter than the distance $(3.54 \AA)$ observed between iodine atoms of different molecules in solid iodine. This indicates an interaction between the $\mathrm{I}_{3}^{-}$ions and the $I_{2}$ molecule in the $I_{8}^{--}$ion. This interaction, however, is much weaker than the interaction between the $I^{-}$ion and the two $I_{2}$ molecules in the $I_{5}^{-}$ion, in which a distance of $3.14 \AA$ is observed between $\mathrm{I}^{-}$and $\mathrm{I}_{2}$ and a distance of 2.93 in $\mathrm{I}_{2}$.

The angle $\left(80^{\circ}\right)$ between $I_{3}^{-}$and $I_{2}$ in $\mathrm{Cs}_{2} \mathrm{I}_{8}$ differs somewhat more from $90^{\circ}$ than in $\mathrm{N}\left(\mathrm{CH}_{3}\right)_{4} \mathrm{I}_{5}\left(94^{\circ}\right)$.

The asymmetry in the $\mathrm{I}_{3}^{-}$ion in $\mathrm{NH}_{4} \mathrm{I}_{3}$, where the two I-I distances are 2.82 and $3 \cdot 10 \AA$ and in which a valence angle I-I-I of $177^{\circ}$ is observed, appears to exist also in the $\mathrm{I}_{3}^{-}$constituents of the $\mathrm{I}_{8}^{--}$ion, where the corresponding values are 2.84 and $3.00 \AA$ respectively.

As little is known about the accuracy of the atomic coordinates in the triiodides, a detailed comparison with $\mathrm{Cs}_{2} \mathrm{I}_{8}$ is not possible. Attempts are being made in our laboratory to determine more accurately the 
dimensions of the $\mathrm{I}_{3}^{-}$ion by a re-investigation of the crystal structure of $\mathrm{CsI}_{3}$.

We are much indebted to Mr S. van der Burg, whose assistance during the experimental part of this work was of great value. It is a pleasure to thank Theodorus Niemeyer N. V. for putting their I.B.M. equipment generously at our disposal and Mr M. R. van der Velde for his assistance. The support of the Netherlands Organisation of Pure Research (Z.W.O.) is also gratefully acknowledged.

\section{References}

Booth, A. D. (1946). Proc. Roy. Soc. A, 188, 77. Briggs, T. R., Greenawaid, J. A. \& Leonard, J. W. (1930). J. Phys. Chem. 34, 1951.

Briggs, T. R. \& Hubard, S. S. (1941). J. Phys. Chem. 45, 806.
Buerger, M. J. (1951). Acta Cryst. 4, 531:

Cruickshank, D. W. J. (1949). Acta Cryst. 2, 65.

Girurs, J. (1948a). Acta Cryst. 1, 76.

Girlis, J. (1948b). Acta Cryst. 1, 174.

HACH, R. J. \& RUNDLE, R. E. (1951). J. Amer. Chem. Soc. $73,4321$.

HARKER, D. \& KASPER, J. S. (1948). Acta Cryst. 1, 70.

HaRris, P. M., MaCk JR., E. \& Blake, F. C. (1928). J. Amer. Chem. Soc. 50, 1599.

Hassel, O. \& Viervoll, A. (1947). Acta Chem. Scand. $1,149$.

Henglein, F. A. \& Roth, R. (1923). Z. anorg. Chem. 126, 227.

Hubard, S. S. (1942). J. Phys. Chem. 46, 227.

Kartha, G. (1952). Acta Cryst. 5, 549.

MoONeY, R. C. L. (1935). Z. Kristallogr. 90, 143.

Wells, H. L., Wheereer, H. L. \& Penfield, S. L. (1893). Z. anorg. Chem. 2, 255.

Wiebenga, E. H. \& Smits, D. W. (1950). Acta Cryst. 3, 265.

WiLson, A. J. C. (1942). Nature, Lond. 150, 152.

Acta Cryst. (1954). 7, 490

\title{
Sign Determination in Crystal Structure Analysis*
}

\author{
By K. Lonsdale and H. J. Grenvinle-Wells $\dagger$ \\ University College, Gower Street, London W.C. 1, England \\ (Received 26 January 1954 and in revised form 25 February 1954)
}

\begin{abstract}
Selection rules (applying to centrosymmetrical crystals only, but for all types of Bravais lattice) are given in tabular form for the correct choice of three X-ray reflexions to which arbitrary signs may be applied as the initial step towards sign determination by statistical methods.
\end{abstract}

Certain direct methods of crystal structure determination depend upon the fact that if the signs of a very few strong reflexions from a centrosymmetrical crystal are known, others can be deduced, at least with a considerable degree of probability.

Zachariasen (1952) has pointed out that 'since the origin may be shifted from one inversion center to another, it is possible to choose the signs of three structure factors at will', and by choosing a positive sign for the reflexions (201), (35 $\overline{3})$ and (017) he succeeded in determining the signs of 198 of the largest Fourier coefficients for monoclinic metaboric acid.

This method can be applied with confidence only if a judicious choice of the original three reflexions is made. $\ddagger$ (These methods are not, of course, always

* All derivations and proofs are omitted from this paper to economize space. The complete paper, in which the rules for axial zones and the list of space groups are also given explicitly, is available in duplicated form on application to the authors.

$\dagger$ I.C.I. Research Fellow.

$\ddagger$ This was first pointed out to us, in principle, in a private conversation with Dr H. Lipson. successful even when correctly applied.) The choice must be such that relative to the eight centres of symmetry in any unit cell (not related by a lattice translation) the signs of the three reflexions will be respectively as shown in Table 1 . For certain combina-

Table 1. Possible combinations of signs of three reflexions $\begin{array}{lllllllll}h_{1} k_{1} l_{1} & + & + & + & + & - & - & - & - \\ h_{2} k_{2} l_{2} & + & + & - & - & - & - & + & + \\ h_{3} k_{3} l_{3} & + & - & + & - & - & + & - & +\end{array}$

tions of reflexions not all these eight possibilities are covered, and in that case the validity of choosing arbitrary signs for three planes is destroyed.

The selection rules depend on the nature of the lattice; apart from this they are independent of system, class or space group, although space-group extinctions may further restrict the choice by reducing to zero intensity some reflexions in axial zones that would otherwise have been allowed.

In this paper we have attempted to show, in a nonmathematical way, the reasons for the selection rules, and to tabulate them so that they can be used directly. 